\title{
Bone Marrow and Adipose Tissue Adenosine Receptors Effect on Osteogenesis and Adipogenesis
}

\author{
Anna Eisenstein ${ }^{1, *}$, Shlok V. Chitalia ${ }^{2}$ and Katya Ravid ${ }^{2}$ \\ 1 Department of Dermatology, Yale School of Medicine, New Haven, CT 06520, USA \\ 2 Department of Medicine and Whitaker Cardiovascular Institute, Boston University School of Medicine, \\ Boston, MA 02118, USA; shlokvipulc@gmail.com (S.V.C.); kravid@bu.edu (K.R.) \\ * Correspondence: anna.eisenstein@yale.edu
}

Received: 2 September 2020; Accepted: 6 October 2020; Published: 10 October 2020

\begin{abstract}
Adenosine is an extracellular signaling molecule that is particularly relevant in times of cellular stress, inflammation and metabolic disturbances when the levels of the purine increase. Adenosine acts on two G-protein-coupled stimulatory and on two G-protein-coupled inhibitory receptors, which have varying expression profiles in different tissues and conditions, and have different affinities for the endogenous ligand. Studies point to significant roles of adenosine and its receptors in metabolic disease and bone health, implicating the receptors as potential therapeutic targets. This review will highlight our current understanding of the dichotomous effects of adenosine and its receptors on adipogenesis versus osteogenesis within the bone marrow to maintain bone health, as well as its relationship to obesity. Therapeutic implications will also be reviewed.
\end{abstract}

Keywords: adenosine receptors; adipogenesis; osteogenesis; adipose tissue; bone marrow; obesity

\section{Introduction}

Adenosine is a nucleoside that is released by all cells, including adipocytes in vitro and the subcutaneous adipose tissue in vivo [1,2]. Adenosine is formed by the degradation of adenosine triphosphate (ATP), adenosine diphosphate (ADP) and adenosine monophosphate (AMP). Levels of adenosine rise in response to metabolic stress, tissue injury, hypoxia and inflammation [3]. Adenosine acts broadly via four receptors. The A1 adenosine receptor (A1AR) and the A3 adenosine receptor (A3AR) are coupled to Gi, which inhibits adenylyl cyclase and decreases cytosolic levels of cyclic AMP (cAMP). The A2a and the A2b adenosine receptors (A2aAR and A2bAR, respectively) are coupled to the stimulatory $G$ alpha protein (Gs), activate adenylyl cyclase and increase cytosolic levels of cAMP. The adenosine receptors may also act on other signaling cascades (Figure 1). The expression of these receptors and the receptor affinity for adenosine allow for modulation of the effect of adenosine in different physiologic states and in different tissues. As such, the action of adenosine may be contradictory depending on these various factors [3]. 




Figure 1. Adenosine Receptor Signaling. The A2aAR and the A2bAR are adenylyl cyclase stimulating receptors through $\mathrm{G} \alpha \mathrm{s}$ subunit. The A1AR and the A3AR are adenylyl cyclase inhibitory receptors through Gai subunit. The A1AR, A3AR and A2bAR also act through phospholipase C (PLC) to increase cytosolic calcium and diacylglycerol (DAG) to activate protein kinase $\mathrm{C}$ (PKC) and MAP kinase (MAPK) signalling. All adenosine receptors are capable of activating phosphatidylinositol 3-kinase (PI3K).

\section{Adenosine Receptors Are Expressed on Bone Marrow-Derived Mesenchymal Stem Cells and Preadipocytes}

Adenosine is found extracellularly under pathologic situations including hypoxia, ischemia or cell damage. Cells release adenosine into the extracellular space through equilibrative nucleoside transporters (ENTs). Adenosine can also be formed by the conversion of extracellular ATP, released from damaged cells, by ectonucleoside triphosphate diphosphorylase (CD39) and ecto-5' -nucleotidase (CD73) enzymes. Adenosine can also be metabolized to inosine by adenosine deaminase or phosphorylated to AMP by adenosine kinase. As one can imagine, the coordination of adenosine release is well regulated at baseline and, during times of cellular stress, can become a signal of disequilibrium [4]. Similarly, while adenosine receptors are present on many different cell types and found generally throughout the body, the level of expression varies in different cell types, pathologic states and developmental stages $[4,5]$, and hence the response to adenosine can be, at times, contradictory. The A1AR and A3AR are more ubiquitously expressed in most tissues, while the A2aAR and the A2bAR have more selective expression [6]. The A1AR is expressed at high levels in the brain, spinal cord, adrenal glands and the heart, with slightly lower expression in the liver, bladder, adipose tissue and testis $[7,8]$. Highest expression of the A3AR occurs in the lung and liver but is also expressed in brain, testis, spleen, thyroid, kidney, bladder, heart, eosinophils and mast cells $[7,8]$. The A2aAR is most highly expressed in the brain, spleen, thymus, leukocytes and platelets; this receptor is also expressed in moderate levels in the heart, lung and vasculature $[7,8]$. The A2bAR is expressed in the vasculature of large intestine, ovaries, testis, liver, spleen, adipose tissue, muscle, pancreas, brain, lung, heart, kidneys, eye and lung [6].

The expression of adenosine receptors is increased in various pathologic conditions (review in $[9,10])$. The A1AR is induced by oxidative stress [11] and hypoxia [12]. The A3AR was found to be upregulated in rheumatoid arthritis and during methotrexate treatment (which increases adenosine levels) as well as in breast and colon cancer [13-16]. The A2aAR is upregulated in inflammatory states $[17,18]$, hypoxia $[19,20]$ and cellular stress such as during food restriction [21]. The A2aAR was also upregulated in individuals receiving methotrexate therapy [16]. Similarly, the A2bAR is 
upregulated by inflammation, hypoxia and extracellular adenosine [22-25]. Expression of the A2bAR is upregulated in conditions of inflammation or hypoxia in the vasculature, intestine, kidneys, heart and lung $[9,19,26,27]$. Not only does the variable and inducible expression of adenosine receptors indicate the complexity of adenosine receptor signaling, it also indicates the consideration that must be taken when designing therapeutics.

Bone-marrow-derived mesenchymal stem cell (MSCs), precursors to adipocytes and osteoblasts, express the A2bAR and the A2aAR [28]. In testing the activity of adenosine receptors in vitro and in vivo, numerous agonists and antagonists have been developed (Table 1). In Ob1771 preadipocytes, the nonspecific adenosine receptor agonist, $5^{\prime}$-N-Ethylcarboxamidoadenosine (NECA), increased cAMP levels, while the A2aAR specific agonist, CGS 21680 (3-(4-(2-((6-amino-9-((2R,3R,4S,5S)5-(ethylcarbomoyl)-3,4-dihydroxytetrahydrofuran-2-yl)-9H-purin-2-yl)amino)ethyl)phenyl)propanoic acid), did not increase cAMP levels, which would suggest that the A2bAR is the predominant adenosine receptor in these preadipocytes [29]. All adenosine receptors and adenosine metabolic and catabolic enzymes (adenosine deaminase, adenosine kinase and CD73) are expressed on MSCs (although no A3AR protein was identified by Western blotting), though at different levels and activities [30]. The A2bAR was shown to be the predominant adenosine receptor subtype, based on a cAMP assay [30].

Table 1. Experimental agonists and antagonists of the adenosine receptors (see the abreviation section for drugs full names).

\begin{tabular}{ccc}
\hline Receptor & Agonist (+)/Antagonist (-) & Drug Acronym \\
\hline A1AR & + & CPA, PIA, CCPA \\
A1AR & - & DPCPX \\
A2aAR & + & CGS 21680 \\
A2aAR & - & SCH442416 \\
A2bAR & + & BAY 60-6583 \\
A2bAR & - & MRS1706, MRS-1754, ATL-801 \\
A3AR & + & IB-MECA, C1-IB-MECA, MRS5698 \\
A3AR & - & MRS1523, MRS1220 \\
All ARs & + & NECA \\
\hline
\end{tabular}

The A1AR is the most highly expressed adenosine receptor in white adipose tissue, followed by the A3AR, A2aAR and A2bAR [31-33]. Adipose tissue can be divided into the mature adipocytes and the stromal vascular fraction, which contains preadipocytes as well as endothelial cells and fibroblasts. The stromal vascular fraction from mice and humans expresses the A2bAR [34]. In vitro, adipocyte precursors (preadipocytes) have a higher expression of the A2aAR and A2bAR, but, following differentiation to a mature adipocyte, there is greater expression of A1AR [29,34-36]. Adenosine receptors are also expressed in adipose tissue. The A2bAR is notably also expressed in other metabolic tissues such as the pancreas, liver and muscle $[6,37,38]$. Moreover, mice fed a high-fat diet (HFD) have increased expression of the A2bAR in the liver, gastrocnemius muscle and the epididymal visceral adipose tissue [37]. Interestingly, the A2bAR mRNA expression is significantly elevated in the subcutaneous adipose tissue of obese individuals as compared to lean individuals [37]. Of interest, adenosine is released from adipocytes. The adenosine content of abdominal subcutaneous adipose tissue has been measured in obese and lean individuals. The levels show a trend towards increased adenosine levels in the adipose tissue of obese $(0.67 \mathrm{pmol} / \mathrm{g}$ wet weight $)$ versus lean $(0.42 \mathrm{pmol} / \mathrm{g}$ wet weight) individuals [39]. Within the bone, osteoclasts express all four adenosine receptors, and mature osteoblasts express A1 and A2bAR [40]. 


\section{Regulation of Adipogenesis and Osteogenesis by Bone Marrow Cell Adenosine Receptors}

Adipogenesis results from the differentiation of adipocyte precursors into mature adipocytes capable of storing lipid in lipid droplets and secreting adipokines as well as cytokines either within the bone marrow or within adipose tissue depots. Adipocyte precursors are found in the bone marrow and within the stromal vascular fraction of peripheral adipose tissue depots. In the bone marrow, adipocytes differentiate from the MSCs, which are common progenitors that are also capable of differentiating into osteoblasts and chondrocytes. The process of adipogenesis requires a cascade of transcription factors. The master regulator of adipogenesis is the nuclear hormone receptor, peroxisome proliferator-activated receptor gamma (PPAR $\gamma$ ). PPAR $\gamma$ is necessary for adipogenesis; mice lacking PPAR $\gamma$ and humans with dominant negative mutations in PPAR $\gamma$ have severe lipodystrophy and are insulin-resistant [41,42]. Moreover, PPAR $\gamma$ expression is sufficient for adipogenesis, as the retroviral expression of PPAR $\gamma$ in cultured fibroblasts resulted in adipogenesis [43]. It is generally thought that in the early stage of adipogenesis, CCAAT enhancer binding protein-beta and -delta (C/EBP- $\beta$ and C/EBP- $\delta$ ) induce the expression of PPAR $\gamma$ and C/EBP- $\alpha$ [44-47].

One of the first studies investigating the role of adenosine receptors in adipogenesis found that the treatment of rat primary preadipocytes with the adenosine analogue, NECA, promoted differentiation [36]. In bone-marrow-derived MSCs, activation of the A2aAR promoted the expression of the above-described adipogenic transcription factors and enhanced adipocyte differentiation, while activation of the A1AR promoted lipogenesis and lipid accumulation in the mature adipocyte [30]. Transfection of the A1AR into a murine osteoblast precursor cell line promoted adipogenesis. In the same model, forced expression of the A2bAR inhibited adipogenesis and promoted osteogenesis [48]. Activation of the A2bAR with BAY 60-6583, an A2bAR-specific agonist, inhibits adipogenesis in ex vivo stromal vascular cells isolated from subcutaneous inguinal adipose tissue [34]. This effect was found to be dependent on the expression of the transcription and differentiation regulator, Krüppel-like factor 4 (KLF4), which was also induced by A2bAR agonism [34]. Notably, while BAY 60-6583 is the most selective A2bAR agonist available, in certain cell lines BAY 60-6583 was reported to act as a partial agonist or even as an antagonist of the A2bAR [49].

Within the bone marrow, there is thought to be a dichotomous relationship between adipogenesis and osteogenesis, whereby the MSC is directed to one lineage or the other. The control of this fate decision is still being investigated. Some research points to adenosine receptors playing a role in dictating the formation of adipocytes or osteoblasts. Clinically, these decisions may manifest during aging, when the bone marrow contains more fat than younger marrow, or in osteoporosis, where there is loss of bone and an accumulation of fat. Transcription factors important for bone development include runt-related gene family members, such as Runx2. Osteoblast differentiation is known to be stimulated by fibroblast growth factor, insulin-like growth factor, bone morphogenic proteins and the Wnt/ $\beta$-catenin pathway.

There has been interest in the role of adenosine and adenosine receptors in bone metabolism. Using pharmacologic inhibitors and A2aAR knock out (KO) mice, the A2aAR was shown to promote proliferation of bone-marrow-derived MSCs [50]. During osteoblast differentiation, the A2bAR is upregulated in the first few days of differentiation, and then is downregulated [30]. Osteoblast differentiation was greater with the nonspecific adenosine receptor agonist, NECA, and this effect was inhibited by the A2bAR antagonist, MRS1706, but not by the A2aAR antagonist, SCH442416. Additionally, the A2aAR agonist, CGS21680, had no effect on bone differentiation [30]. This all suggests that the A2bAR is the predominant adenosine receptor in augmenting osteoblast differentiation. These findings were supported and advanced in the study by Carroll et al. Using an A2bAR-specific agonist and A2bAR KO mice, the authors showed that activation of the A2bAR promotes osteoblast differentiation [28]. Furthermore, microcomputed tomography analysis of adult femurs from A2bAR $\mathrm{KO}$ and wild type (WT) mice showed lower bone density in the KO mice compared to the WT mice [28]. In addition, the A2bAR KO mice had delayed fracture repair as compared to the WT mice [28]. In a study of A2bAR KO from youth to adult age, alterations in bone homeostasis were 
observed in the $\mathrm{KO}$ mice. Most notably, there was a decrease in bone mineral density and trabecular volume as well as reduced formation of new bone in A2bAR KO mice as compared to WT mice [51]. In contrast, the application of an A2bAR agonist reduced bone loss in ovariectomized mice [52], underscoring the need to carefully evaluate the results based on the usage of ligands versus genetic ablation. Regarding the A1AR, pharmacologic inhibition of or genetic knockout of this receptor in mice impairs osteoclast differentiation [53,54]. Furthermore, A1AR KO mice that were ovariectomized, as a model of post-menopausal bone loss, maintained bone volume and had decreased osteoclast bone resorption compared to wild type [55]. Importantly, treatment with an A1AR antagonist prevented ovariectomy-induced bone loss [55]. Conversely, A2aAR agonists have been shown to inhibit osteoclast differentiation and function, and femurs from $\mathrm{A} 2 \mathrm{aAR} \mathrm{KO}$ mice had decreased bone volume to trabecular bone volume ratio and increased osteoclasts [56]. Thus, the A2bAR and the A2aAR both regulate bone turnover by affecting the osteoblast and osteoclast lineages, respectively. In a study utilizing human bone marrow cells, similar results were found: notably, that inhibition of the A1AR and activation of the A2aAR and A2bAR inhibits osteoclast formation, while A2bAR and A2aAR promote osteoblast formation [57].

The ectonucleotidase CD73, which regulates levels of extracellular adenosine through the metabolism AMP to adenosine, plays an important role in bone metabolism. CD73 KO mice have impaired osteoblast differentiation and decreased bone formation with the development of osteopenia [58]. In vitro, this was found to be mediated by the A2bAR, and this is more fully reviewed in the above section [58]. CD73 was also found to be important for bone repair following injury in aged mice [59]. The expression of CD39, which hydrolyzes ATP and ADP, and CD73 as well as adenosine levels in the bone marrow, were found to be decreased in a mouse model of osteoporosis. This same group also found that an A2bAR agonist reduced bone loss in ovariectomized mice [52]. A more recent study reported CD39 on gingiva-derived mesenchymal stem cells as a promoter of osteogenesis through the Wnt/ $\beta$-catenin signaling pathway [60].

While the above studies focus on the cellular mechanism of osteogenesis, further direct investigation is needed on the effect of adenosine and its receptors on bone density in humans. Due to the beneficial effect of activation of adenosine receptors on bone density in various mice models [61-63], Zarebska et al. investigated the influence of exercise endurance on plasma ATP levels with the hypothesis that ATP concentration, a predecessor molecule of adenosine, is likely to correlate with exercise level [63]. This was a one-year study that compared 18 to 34-year old athletes, including futsal players, sprinters and endurance athletes, to a control group. A treadmill test was taken until the participants reached exhaustion and ATP levels were measured. There were higher ATP levels in athletes who had better exercise endurance, postulating a resulting increase in adenosine and adenosine receptor activation. Further studies are warranted to elucidate the contribution of adenosine receptor activation under different physiological conditions, including exercise and with varying bone density.

\section{Adenosine Receptors in Glucose Homeostasis and Obesity}

The function of the A1AR in inhibiting lipolysis has been extensively studied. It is thought that endogenously released adenosine maintains a constant inhibitory signal to adipocyte lipolysis. When adenosine deaminase, which removes endogenous adenosine by degrading it to inosine, is added to the culture of adipocytes from fasted rats, lipolysis reaches maximal levels [64,65]. It has also been shown that adipocytes isolated from humans have a similar response to A1AR agonism, such that treatment with PIA, an A1AR agonist, inhibits isoprenaline-stimulated lipolysis [39]. Conversely, when an A1AR antagonist, 8-Cyclopentyl-1,3-dipropylxanthine (DPCPX), was applied to rat adipocytes, lipolysis increased [66]. A different A1AR antagonist, 8-phenyltheophylline, also increased lipolysis in adipocytes from obese Zucker (fa/fa) rats [67]. When an A1AR agonist was given to Wistar and Zucker fatty rats, levels of free fatty acids, glycerol and triglycerides were reduced $[33,68]$. These findings were also verified in A1AR KO mice. In these conditions, when an adenosine analog, 2-chloroadenosine, was added to A1AR KO adipocytes, there was no inhibition of lipolysis, as occurred in control WT 
mice [69]. Furthermore, systemic administration of N-Cyclopentyladenosine (CPA), an A1AR agonist, reduced plasma levels of free fatty acids, glycerol and triglycerides (reducing lipolysis) in WT but not A1AR KO mice. Importantly, A1AR KO mice at baseline had elevated free fatty acids as compared to WT mice, suggesting a tonic-suppressive effect on lipolysis by adenosine through the A1AR in vivo [69]. Furthermore, the body weight of A1AR KO mice was significantly increased by $7-8.5 \%$ in older ( $>5$ months) male as compared to controls [69]. Conversely, in aged A1AR KO mice (14-16 months old), the KO mice weighed slightly less than WT age-matched controls, with more lean mass and less abdominal fat mass [70]. Correspondingly, aged A1AR KO mice had better glucose tolerance and insulin sensitivity systemically and within visceral adipose tissue [70]. In an HFD model of obesity, A1AR KO mice were heavier than WT mice, had elevated fasting plasma and insulin levels and had impaired glucose clearance, as determined in hyperinsulinemic-euglycemic clamp studies [71]. Overexpression of the A1AR in the adipose tissue of mice resulted in decreased plasma free fatty acid levels as compared to controls [72]. There was no effect on body weight on a normal chow diet or with HFD challenge. Interestingly, overexpression of the A1AR was protective against insulin resistance [72]. Adipocytes from lean individuals as compared to obese individuals were more responsive to the effect of A1AR agonism on reducing lipolysis. The mechanism for this effect was shown to be a result of a greater ability of A1AR agonist to decrease adenylate cyclase activity in adipocytes from lean individuals. The role of the A1AR on leptin secretion by adipocytes has also been studied [73]. Sprague-Dawley rats were treated with the A1AR-selective agonist, CPA (N6-Cyclopentyladenosine), and serum leptin levels were measured. Interestingly, stimulation of the A1AR increased leptin concentration in the serum, a finding that was not seen in the vehicle-treated rats. The authors contend that this finding was a result of increased secretion of pre-formed leptin, as the mRNA levels of leptin did not change with A1AR activation. This finding would fit with the idea that leptin secretion is negatively regulated by cAMP. A1AR agonism of adipocytes from lean and obese individuals revealed enhanced glucose uptake with A1AR agonism by PIA in adipocytes from lean individuals as compared to obese individuals [39]. During glucose challenge, freely fed A1AR KO mice have increased insulin and glucagon secretion, though no difference was seen in plasma glucose as compared to WT mice [32]. Clearly, A1ARs play an important role in lipid homeostasis, a consideration that should be made when developing therapeutic targets of the A1AR.

The A2bAR has also been studied in the context of lipid and glucose homeostasis. Koupenova et al. showed that lack of the A2bAR in ApoE-deficient mice fed a HFD resulted in elevated liver and plasma cholesterol and triglycerides, hepatic steatosis and atherosclerotic plaques [38]. Furthermore, administration of the A2bAR agonist, BAY 60-6583 (2-[[6-Amino-3,5-dicyano-4[4-(cyclopropylmethoxy)penyl]-2-pyridinyl]thio]-acetamide) to ApoE-deficient mice on HFD reduced atherosclerotic plaque formation and circulating plasma triglycerides and cholesterol [38]. In a type I diabetes model, the adenosine receptor agonist, NECA, reduced plasma glucose levels and ameliorated the diabetes-induced decrease in pancreatic insulin [74]. In an attempt to determine which adenosine receptor was responsible for this effect of NECA, the authors found that the A1AR agonist, 2-Chloro-N6-cyclopentyladenosine (CCPA), decreased hyperglycemia, but to a lesser extent than that of NECA. The A2aAR agonist, CGS21680, did not alter glucose levels and NECA was able to suppress hyperglycemia in A2aAR KO, suggesting that this receptor was not playing a significant role. When NECA and an A2bAR antagonist, MRS 1754, were injected together, the suppressive effect of NECA was abolished, suggesting that the NECA action through the A2bAR played a dominant role in reducing plasma glucose in this model [74]. In one study, KKAy mice (named after Kyoji Kondo who developed a diabetic mouse strain) were used to model type 2 diabetes mellitus. In this case, administration of the A2bAR antagonist, ATL-801, for two days reduced hepatic glucose production and increased glucose uptake in skeletal muscle and brown adipose tissue [75]. Acute challenge with the adenosine receptor agonist, NECA, delayed glucose disposal and increased fasting glucose levels [75]. This effect was eliminated in A2bAR KO mice, which suggests that NECA activation of the A2bAR impaired glucose uptake and utilization [75]. On the other hand, A2bAR KO mice 
fed an HFD for 16 weeks have increased adiposity, delayed glucose clearance and impaired insulin sensitivity [37]. Intraperitoneal injection of the A2bAR-specific agonist, BAY 60-6583, during HFD feeding lowered fasting glucose levels and improved glucose and insulin tolerance [37]. Further work showed that restoration of macrophage expression of A2bAR in an otherwise full-body A2bAR KO mouse restored insulin signaling and glucose homeostasis to the levels of WT mice [76]. Furthermore, glucose homeostasis and systemic and tissue inflammatory markers were ameliorated with restoration of A2bAR signaling in macrophages [76]. In a third model, A2bAR KO mice fed a chow diet, but not an HFD, gained more weight and had impaired glucose and lipid homeostasis as compared to WT mice [77]. This effect was shown to be a result of the ability of A2bAR to promote alternative macrophage activation and prevent adipose tissue inflammation [77]. The role of the A2bAR in insulin and glucose sensitivity has been extensively studied in mouse models of obesity and diabetes and appears to play an active role in maintaining glucose homeostasis $[37,78]$.

The A2aAR has also been implicated in adipose tissue dynamics, obesity and inflammation. Mice fed a HFD for 12 weeks had increased expression of the A2aAR in macrophages within the adipose tissue as compared to mice on a low-fat diet [79]. These macrophages were also more proinflammatory (M1) as compared to WT mice [79]. A2aAR KO mice fed an HFD gained more weight than WT mice, despite similar food consumption and energy expenditure [79]. A2aAR KO mice had greater abdominal fat mass, increased adipocyte size than WT mice, greater insulin resistance and glucose intolerance $[79,80]$. Furthermore, in another study, A2aAR KO mice fed an HFD for 16 weeks had reduced glucose tolerance due to a decrease in insulin secretion by the pancreas rather than a difference in insulin sensitivity [81]. In an HFD model of obesity in Swiss mice, the administration of CGS21680, an A2aAR agonist, improved glucose homeostasis, as determined by insulin tolerance test, and reduced inflammatory markers such as tumor necrosis factor alpha (TNF $\alpha$ ) systemically and in the visceral adipose tissue [82]. Overall, activation of the A2aAR may also be a potential therapeutic target in metabolic disease.

An exciting study explored the effect of the A2aAR on brown adipose tissue. The authors found that the A2aAR is the most highly expressed adenosine receptor in brown adipose tissue [31]. A2aAR KO mice or pharmacologic inhibition of the A2aAR decreased thermogenesis [31]. Conversely, the administration of A2aAR agonists increased energy expenditure [31]. This finding was explained by browning of the white adipose tissue which was induced by activation of the A2aAR [31]. Finally, in mice fed an HFD, administration of an A2aAR agonist decreased weight gain and improved glucose tolerance [31]. Ruan et al. showed that A2aAR expression in brown adipose tissue was important in cardiac remodeling during hypertension [83]. A2aAR KO mice had worsened hypertensive cardiac remodeling compared to WT mice in a mouse model of hypertension [83]. The A2aAR was highly induced in the brown adipose tissue in this model, and lack of the A2aAR in KO mice impaired brown adipose tissue thermogenesis induced by the hypertensive model in WT mice [83]. Furthermore, A2aAR-induced thermogenesis in brown adipose tissue was important for secretion of fibroblast growth factor 21 (FGF21), which was necessary to protect against hypertension-induced cardiac remodeling [83]. In a study in lean men using Positron Emission Tomography-Computed Tomography (PET/CT), adenosine was found to increase perfusion in brown adipose tissue to a greater extent than cold exposure [84]. Interestingly, using the PET radioligand, $\left[{ }^{11} \mathrm{C}\right] \mathrm{TMSX}$, which binds specifically to the A2aAR, lean men were found to have reduced brown adipose tissue radioligand binding (a marker of A2aAR receptor density) following cold exposure [84]. However, in mice lacking all four ARs, termed quadruple knockout mice (QKO), body temperature did not differ from WT mice [85], suggesting that ARs are not necessary for baseline body temperature or that the four adenosine receptors may have reciprocal and opposing effects on body temperature such that deletion of one adenosine receptor is balanced by the deletion of a different adenosine receptor. Regardless, the role of the $\mathrm{A} 2 \mathrm{aAR}$ in brown adipose tissue appears to be clinically relevant and may lead to future therapeutic efforts. 
Gnad et al. evaluated the effect of A2bAR stimulation or suppression in major energy dissipating tissues [86]. Their studies demonstrated a significant expression of A2bAR in skeletal muscle and brown adipose tissues. Upon genetic deletion of the A2bAR specifically in the skeletal muscle of mice, there was loss of muscle mass, exemplified by sarcopenia and reduced energy expenditure. A2bAR activation had opposite effects. Similarly, the deletion of A2bAR specifically in adipose tissue increased age-related reduction in brown adipose tissue, while stimulation of the A2bAR protected brown adipose tissue, and reduced white adipose tissue and obesity. This study demonstrates the beneficial effect of A2bAR stimulation on several cell types important in thermogenesis and in preventing obesity and age-related sarcopenia. Future studies are needed to understand how this receptor stimulation mediates this effect, especially in complex disease models consisting of other pathological processes accompanying obesity, such as diabetes.

\section{Discussion: Implications for Therapeutic Benefit}

Adenosine receptors play a role in regulating adipogenesis in peripheral adipose tissue and the bone marrow, and influence whole-body metabolism in terms of lipid storage and glucose homeostasis. Given the potential therapeutic benefits of adenosine receptors, this is an exciting time in adenosine biology. Given the complex biology and diverse, and, at times, contradictory effects of the adenosine receptors, continued development and study of drugs that target specific adenosine receptors will be key to the ultimate goal of creating therapeutic agents that lack potential adverse influences (thoroughly reviewed in [87]).

As shown in Table 2, several A1AR agonists, including SDZWAG994, ARA and RPR749, have been evaluated in humans as antilipolytic agents for hypertriglyceridemia [88-90]. RPR749 is an orally active A1AR agonist. In a double-blind, single increasing dose, placebo-controlled, parallel group randomized study, six parallel groups of eight men (six individuals in the active arm and two in the placebo arm in each group) were given RPR749 or control as a single dose. The average free fatty acid concentration in the serum decreased in all treatment groups [90]. Unfortunately, A1AR agonists have significant side effects, including in the heart and kidney, and also become desensitized after repeated exposure. Partial agonists like GS-9667 (previously known at CVT-3619), decreased plasma free fatty acids without desensitization or significant side effects in rodents [91,92]. In a single ascending dose study, healthy non-obese and obese individuals were given a single oral dose of GS-9667 and, in a multiple ascending dose study, healthy obese subjects received GS-9667 for 14 days. The studies found that GS-9667 resulted in decreased free fatty acid levels in a dose-dependent manner, which was maintained over the 14 days of treatment [93]. In addition to the above-cited side effects identified in these trials, the additional consequences of A1AR agonism in the long term may include effects on bone homeostasis with potential for greater risk of osteoporosis.

Table 2. A1AR Modulators Trialed in Humans.

\begin{tabular}{cccc}
\hline Receptor & Activity & Drug Acronym & Therapeutic Target (Reference) \\
\hline A1AR & Agonist & SDZWAG994 & Hypertriglyceridemia [88] \\
A1AR & Agonist & ARA & Hypertriglyceridemia [89] \\
A1AR & Agonist & RPR749 & Hypertriglyceridemia [90] \\
A1AR & Partial agonist & GS-9667 & Hyperlipidemia [91] \\
\hline
\end{tabular}

Other exciting potential targets include the $\mathrm{A} 2 \mathrm{bAR}$, given its reported role in improving glucose and insulin homeostasis, and the A2aAR, given its reported ability to promote thermogenesis and browning of the white adipose tissue. However, given the potential for alterations in bone metabolism and other off-target effects, caution should be applied when evaluating adenosine receptor modulators. Much effort has been devoted to the synthesis of therapeutic drugs that target adenosine receptors, but several clinical trials have failed, and few such drugs are approved. Adenosine itself and regadenoson, an A2aAR agonist, are both approved for coronary stress imaging and for the treatment 
of paroxysmal supraventricular tachycardia in the case of adenosine. The first adenosine receptor antagonist to be FDA-approved is the A2aAR antagonist istradefylline (Nourianz), which is used with levodopa/carbidopa in Parkinson's disease [94]. While istradefylline had a good safety profile in over 4000 patients tested with this drug, a different A2aAR antagonist led to death from agranulocytosis in five patients in a phase III clinical trial [95]. An ongoing review of the approved A2aAR antagonist will be necessary to determine if there are long-term consequences, including impairment in bone or adipose tissue metabolism.

Author Contributions: Conceptualization, A.E., K.R.; writing—original outline and first draft preparation, A.E., K.R.; writing-review, supplementing and editing, A.E., S.V.C., K.R. All authors have read and agreed to the published version of the manuscript.

Funding: A.E. receives funding from the NIH/NIAMS 5T32AR007016-45 grant and from the Dermatology Foundation. K.R. is funded by NIH grant UL1TR001430.

Conflicts of Interest: The authors declare no conflict of interest.

\section{Abbreviations}

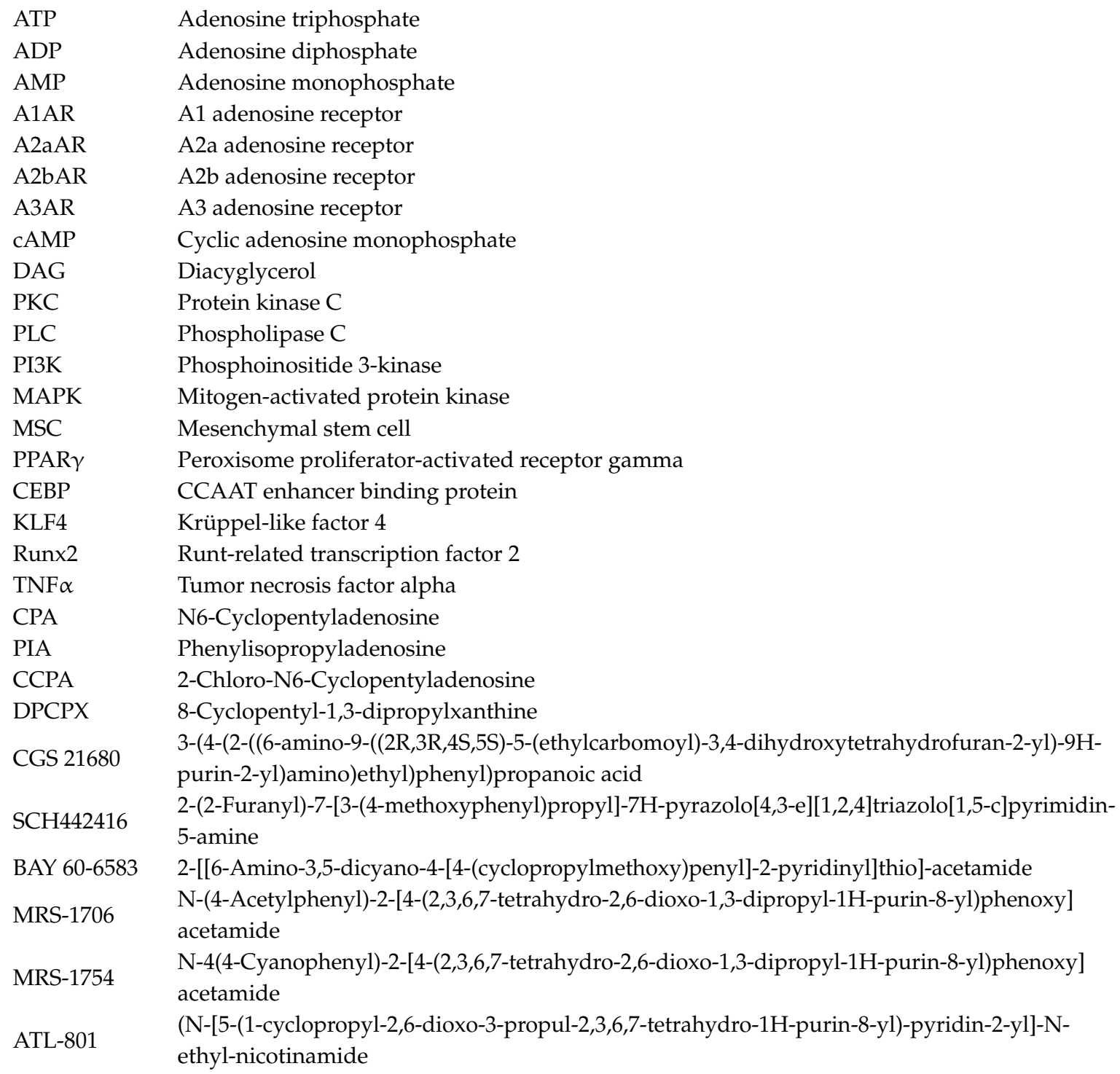


IB-MECA $\quad \mathrm{N}^{6}$-(3-Iodobenzyl)adenosine-5'-N-methyluronamide

C1-IB-MECA 2-Chloro-N ${ }^{6}$-(3-Iodobenzyl)adenosine-5'-N-methyluronamide

MRS5698 (1S,2R,3S,4R,5S)-4-[6-[[(3-Chlorophenyl)methyl]amino]-2-[2-(3,4-difluorophenyl)ethynyl]-9H-

purin-9-yl]-2,3-dihydroxy-N-methylbicyclo[3.1.0]hexane-1-carboxamide

MRS1523 3-Propyl-6-ethyl-5-[(ethylthio)carbonyl]-2 phenyl-4-propyl-3-pyridine carboxylate

MRS1220 N-[9-Chloro-2-(2-furanyl)[1,2,4]-triazol[1,5-c]quinazolin-5-yl]benzene acetamide

NECA $\quad 5^{\prime}$-N-Ethylcarboxamidoadenosine

SDZWAG994 N-Cyclohexyl-2'-O-methyladenosine

ARA

RPR749 ([1S,2R,3R,5R]-3-methoxymethyl-5-[6-(1-[5-trifluoromethyl-pyridin-2-yl]pyrrolidine-3-[S]ylamino)-purin-9-yl]cyclopentane-1,2-diol)

GS-9667 $\mathrm{C}_{22} \mathrm{H}_{26} \mathrm{~F}_{3} \mathrm{~N}_{7} \mathrm{O}_{3}$ (2S,3S,4R,5R)-2-(((2-fluorophenyl)thio)methyl)-5-(6-(((1R,2R)-2-hydroxycyclopentyl)amino)-9Hpurin-9-yl)tetrahydrofuran-3,4-diol

\section{References}

1. Fredholm, B.B. Release of Adenosine-like Material from Isolated Perfused Dog Adipose Tissue Following Sympathetic Nerve Stimulation and its Inhibition by Adrenergic $\alpha$-Receptor Blockade. Acta Physiol. Scand. 1976, 96, 422-430. [CrossRef] [PubMed]

2. Schwabe, U.; Ebert, R.; Erbler, H.C. Adenosine release from isolated fat cells and its significance for the effects of hormones on cyclic 3',5'-AMP levels and lipolysis. Naunyn Schmiedebergs Arch. Pharmacol. 1973, 276, 133-148. [CrossRef] [PubMed]

3. Fredholm, B.B. Adenosine-a physiological or pathophysiological agent? J. Mol. Med. 2013, 92, $201-206$. [CrossRef]

4. Borea, P.A.; Gessi, S.; Merighi, S.; Varani, K. Adenosine as a Multi-Signalling Guardian Angel in Human Diseases: When, Where and How Does it Exert its Protective Effects? Trends Pharmacol. Sci. 2016, 37, 419-434. [CrossRef] [PubMed]

5. Peleli, M.; Fredholm, B.B.; Sobrevia, L.; Carlstrom, M. Pharmacological targeting of adenosine receptor signaling. Mol. Asp. Med. 2017, 55, 4-8. [CrossRef]

6. Yang, D.; Zhang, Y.; Nguyen, H.G.; Koupenova, M.; Chauhan, A.K.; Makitalo, M.; Jones, M.R.; Hilaire, C.S.; Seldin, D.C.; Toselli, P.; et al. The A2B adenosine receptor protects against inflammation and excessive vascular adhesion. J. Clin. Investig. 2006, 116, 1913-1923. [CrossRef]

7. Dixon, A.K.; Gubitz, A.K.; Sirinathsinghji, D.J.; Richardson, P.J.; Freeman, T.C. Tissue distribution of adenosine receptor mRNAs in the rat. Br. J. Pharmacol. 1996, 118, 1461-1468. [CrossRef]

8. Fredholm, B.B.; Arslan, G.; Halldner, L.; Kull, B.; Schulte, G.; Wasserman, W. Structure and function of adenosine receptors and their genes. Naunyn-Schmiedeberg's Arch. Pharmacol. 2000, 362, 364-374. [CrossRef]

9. Poth, J.M.; Brodsky, K.; Ehrentraut, H.; Grenz, A.; Eltzschig, H.K. Transcriptional control of adenosine signaling by hypoxia-inducible transcription factors during ischemic or inflammatory disease. J. Mol. Med. 2012, 91, 183-193. [CrossRef]

10. Hilaire, C.S.; Carroll, S.H.; Chen, H.; Ravid, K. Mechanisms of induction of adenosine receptor genes and its functional significance. J. Cell. Physiol. 2009, 218, 35-44. [CrossRef]

11. Karmazyn, M.; A Cook, M. Adenosine A1 receptor activation attenuates cardiac injury produced by hydrogen peroxide. Circ. Res. 1992, 71, 1101-1110. [CrossRef] [PubMed]

12. Prabhakar, N.R.; Kumar, G.K. Oxidative stress in the systemic and cellular responses to intermittent hypoxia. Biol. Chem. 2004, 385, 217-221. [CrossRef] [PubMed]

13. Madi, L.; Cohen, S.; Ochayin, A.; Bar-Yehuda, S.; Barer, F.; Fishman, P. Overexpression of A3 adenosine receptor in peripheral blood mononuclear cells in rheumatoid arthritis: Involvement of nuclear factor-kappaB in mediating receptor level. J. Rheumatol. 2007, 34, 20-26.

14. Madi, L.; Ochaion, A.; Rath-Wolfson, L.; Bar-Yehuda, S.; Erlanger, A.; Ohana, G.; Harish, A.; Merimski, O.; Barer, F.; Fishman, P. The A3 Adenosine Receptor Is Highly Expressed in Tumor versus Normal Cells. Clin. Cancer Res. 2004, 10, 4472-4479. [CrossRef] [PubMed] 
15. Ochaion, A.; Bar-Yehuda, S.; Cohn, S.; Del Valle, L.; Perez-Liz, G.; Madi, L.; Barer, F.; Farbstein, M.; Fishman-Furman, S.; Reitblat, T.; et al. Methotrexate enhances the anti-inflammatory effect of CF101 via up-regulation of the A3 adenosine receptor expression. Arthritis Res. Ther. 2006, 8, R169. [CrossRef] [PubMed]

16. Singh, A.; Misra, R.; Aggarwal, A. Baseline adenosine receptor mRNA expression in blood as predictor of response to methotrexate therapy in patients with rheumatoid arthritis. Rheumatol. Int. 2019, 39, 1431-1438. [CrossRef] [PubMed]

17. Morello, S.; Ito, K.; Yamamura, S.; Lee, K.-Y.; Jazrawi, E.; DeSouza, P.; Barnes, P.; Cicala, C.; Adcock, I.M. IL-1 beta and TNF-alpha regulation of the adenosine receptor (A2A) expression: Differential requirement for NF-kappa B binding to the proximal promoter. J. Immunol. 2006, 177, 7173-7183. [CrossRef]

18. Murphree, L.J.; Sullivan, G.W.; Marshall, M.A.; Linden, J. Lipopolysaccharide rapidly modifies adenosine receptor transcripts in murine and human macrophages: Role of NF- $\mathrm{KB}$ in A2Aadenosine receptor induction. Biochem. J. 2005, 391, 575-580. [CrossRef]

19. Ahmad, A.; Ahmad, S.; Glover, L.E.; Miller, S.M.; Shannon, J.M.; Guo, X.; Franklin, W.A.; Bridges, J.P.; Schaack, J.B.; Colgan, S.P.; et al. Adenosine A2A receptor is a unique angiogenic target of HIF-2 in pulmonary endothelial cells. Proc. Natl. Acad. Sci. USA 2009, 106, 10684-10689. [CrossRef]

20. Kobayashi, S.; Beitner-Johnson, D.; Conforti, L.; Millhorn, D.E. Chronic hypoxia reduces adenosine A2A receptor-mediated inhibition of calcium current in rat PC12 cells via downregulation of protein kinase A. J. Physiol. 1998, 512, 351-363. [CrossRef]

21. Di Bonaventura, M.V.E.; Pucci, M.; Giusepponi, M.E.; Romano, A.; Lambertucci, C.; Volpini, R.; Di Bonaventura, E.M.; Gaetani, S.; Maccarrone, M.; D'Addario, C.; et al. Regulation of adenosine A2A receptor gene expression in a model of binge eating in the amygdaloid complex of female rats. J. Psychopharmacol. 2019, 33, 1550-1561. [CrossRef]

22. Kong, T.; Westerman, K.A.; Faigle, M.; Eltzschig, H.K.; Colgan, S.P. HIF-dependent induction of adenosine A2B receptor in hypoxia. FASEB J. 2006, 20, 2242-2250. [CrossRef] [PubMed]

23. Lan, J.; Lu, H.; Samanta, D.; Salman, S.; Lu, Y.; Semenza, G.L. Hypoxia-inducible factor 1-dependent expression of adenosine receptor 2B promotes breast cancer stem cell enrichment. Proc. Natl. Acad. Sci. USA 2018, 115, E9640-E9648. [CrossRef] [PubMed]

24. Sitkovsky, M.V.; Ohta, A. The 'danger' sensors that STOP the immune response: The A2 adenosine receptors? Trends Immunol. 2005, 26, 299-304. [CrossRef]

25. Yang, M.; Ma, C.; Liu, S.; Shao, Q.; Gao, W.; Song, B.; Sun, J.; Xie, Q.; Zhang, Y.; Feng, A.; et al. HIF-dependent induction of adenosine receptor $\mathrm{A} 2 \mathrm{~b}$ skews human dendritic cells to a Th2-stimulating phenotype under hypoxia. Immunol. Cell Biol. 2009, 88, 165-171. [CrossRef] [PubMed]

26. Eckle, T.; Kewley, E.M.; Brodsky, K.S.; Tak, E.; Bonney, S.; Gobel, M.; Anderson, D.; Glover, L.E.; Riegel, A.K.; Colgan, S.P.; et al. Identification of Hypoxia-Inducible Factor HIF-1A as Transcriptional Regulator of the A2B Adenosine Receptor during Acute Lung Injury. J. Immunol. 2014, 192, 1249-1256. [CrossRef] [PubMed]

27. Kwon, J.H.; Lee, J.; Kim, J.; Jo, Y.H.; Kirchner, V.A.; Kim, N.; Kwak, B.J.; Hwang, S.; Song, G.; Lee, S.; et al. HIF-1 $\alpha$ regulates A2B adenosine receptor expression in liver cancer cells. Exp. Ther. Med. 2019, 18, 4231-4240. [CrossRef] [PubMed]

28. Carroll, S.H.; Wigner, N.A.; Kulkarni, N.; Johnston-Cox, H.; Gerstenfeld, L.C.; Ravid, K. A2B adenosine receptor promotes mesenchymal stem cell differentiation to osteoblasts and bone formation in vivo. J. Biol. Chem. 2012, 287, 15718-15727. [CrossRef] [PubMed]

29. Børglum, J.; Vassaux, G.; Richelsen, B.; Gaillard, D.; Darimont, C.; Ailhaud, G.; Négrel, R.; Richelsen, B. Changes in adenosine A1- and A2-receptor expression during adipose cell differentiation. Mol. Cell. Endocrinol. 1996, 117, 17-25. [CrossRef]

30. Gharibi, B.; Abraham, A.A.; Ham, J.; Evans, B.A.J. Adenosine receptor subtype expression and activation influence the differentiation of mesenchymal stem cells to osteoblasts and adipocytes. J. Bone Miner. Res. 2011, 26, 2112-2124. [CrossRef]

31. Gnad, T.; Scheibler, S.; Von Kügelgen, I.; Scheele, C.; Kilić, A.; Glöde, A.; Hoffmann, L.S.; Reverte-Salisa, L.; Horn, P.; Mutlu, S.; et al. Adenosine activates brown adipose tissue and recruits beige adipocytes via A2A receptors. Nat. Cell Biol. 2014, 516, 395-399. [CrossRef] [PubMed] 
32. Johansson, S.M.; Salehi, A.; Sandström, M.E.; Westerblad, H.; Lundquist, I.; Carlsson, P.-O.; Fredholm, B.B.; Katz, A. A1 receptor deficiency causes increased insulin and glucagon secretion in mice. Biochem. Pharmacol. 2007, 74, 1628-1635. [CrossRef] [PubMed]

33. Schoelch, C.; Kuhlmann, J.; Gossel, M.; Mueller, G.; Neumann-Haefelin, C.; Belz, U.; Kalisch, J.; Biemer-Daub, G.; Kramer, W.; Juretschke, H.-P.; et al. Characterization of adenosine-A1 receptor-mediated antilipolysis in rats by tissue microdialysis, $1 \mathrm{H}$-spectroscopy, and glucose clamp studies. Diabetes 2004, 53, 1920-1926. [CrossRef] [PubMed]

34. Eisenstein, A.; Carroll, S.H.; Johnston-Cox, H.; Farb, M.; Gokce, N.; Ravid, K. An Adenosine Receptor-Krüppel-like Factor 4 Protein Axis Inhibits Adipogenesis. J. Biol. Chem. 2014, 289, 21071-21081. [CrossRef] [PubMed]

35. Ravid, K.; Lowenstein, J.M. Changes in adenosine receptors during differentiation of 3T3-F442A cells to adipocytes. Biochem. J. 1988, 249, 377-381. [CrossRef] [PubMed]

36. Vassaux, G.; Gaillard, D.; Mari, B.; Ailhaud, G.; Négrel, R. Differential Expression of Adenosine A1 and Adenosine A2 Receptors in Preadipocytes and Adipocytes. Biochem. Biophys. Res. Commun. 1993, 193, 1123-1130. [CrossRef]

37. Johnston-Cox, H.; Koupenova, M.; Yang, D.; Corkey, B.; Gokce, N.; Farb, M.G.; Lebrasseur, N.K.; Ravid, K. The A2b Adenosine Receptor Modulates Glucose Homeostasis and Obesity. PLoS ONE 2012, 7, e40584. [CrossRef]

38. Koupenova, M.; Johnston-Cox, H.; Vezeridis, A.; Gavras, H.; Yang, D.; Zannis, V.I.; Ravid, K. A2b adenosine receptor regulates hyperlipidemia and atherosclerosis. Circulation 2011, 125, 354-363. [CrossRef]

39. Kaartinen, J.M.; Hreniuk, S.P.; Martin, L.F.; Ranta, S.; LaNoue, K.F.; Ohisalo, J.J. Attenuated adenosine-sensitivity and decreased adenosine-receptor number in adipocyte plasma membranes in human obesity. Biochem. J. 1991, 279, 17-22. [CrossRef]

40. Hajjawi, M.O.R.; Patel, J.J.; Corcelli, M.; Arnett, T.; Orriss, I.R. Lack of effect of adenosine on the function of rodent osteoblasts and osteoclasts in vitro. Purinergic Signal. 2016, 12, 247-258. [CrossRef]

41. Barroso, I.; Gurnell, M.; Crowley, V.E.F.; Agostini, M.; Schwabe, J.W.; Soos, M.A.; Maslen, G.L.; Williams, T.D.M.; Lewis, H.; Schafer, A.J. Dominant negative mutations in human PPARgamma associated with severe insulin resistance, diabetes mellitus and hypertension. Nature 1999, 402, 880-883. [CrossRef] [PubMed]

42. Wang, F.; Mullican, S.E.; DiSpirito, J.R.; Peed, L.C.; Lazar, M.A. Lipoatrophy and severe metabolic disturbance in mice with fat-specific deletion of PPARgamma. Proc. Natl. Acad. Sci. USA 2013, 110, 18656-18661. [CrossRef] [PubMed]

43. Tontonoz, P.; Hu, E.; Spiegelman, B.M. Stimulation of adipogenesis in fibroblasts by PPAR gamma 2, a lipid-activated transcription factor. Cell 1994, 79, 1147-1156. [CrossRef]

44. Cao, Z.; Umek, R.M.; McKnight, S.L. Regulated expression of three C/EBP isoforms during adipose conversion of 3T3-L1 cells. Genes Dev. 1991, 5, 1538-1552. [CrossRef] [PubMed]

45. Steger, D.J.; Grant, G.R.; Schupp, M.; Tomaru, T.; Lefterova, M.I.; Schug, J.; Manduchi, E.; Stoeckert, C.J.; Lazar, M.A. Propagation of adipogenic signals through an epigenomic transition state. Genes Dev. 2010, 24, 1035-1044. [CrossRef] [PubMed]

46. Tanaka, T.; Yoshida, N.; Kishimoto, T.; Akira, S. Defective adipocyte differentiation in mice lacking the C/EBPbeta and/or C/EBPdelta gene. EMBO J. 1997, 16, 7432-7443. [CrossRef]

47. Wu, Z.; Bucher, N.L.; Farmer, S.R. Induction of peroxisome proliferator-activated receptor gamma during the conversion of $3 \mathrm{~T} 3$ fibroblasts into adipocytes is mediated by C/EBPbeta, C/EBPdelta, and glucocorticoids. Mol. Cell. Biol. 1996, 16, 4128-4136. [CrossRef]

48. Gharibi, B.; Abraham, A.A.; Ham, J.; Evans, B.A.J. Contrasting effects of A1 and A2b adenosine receptors on adipogenesis. Int. J. Obes. 2011, 36, 397-406. [CrossRef]

49. Hinz, S.; Lacher, S.K.; Seibt, B.F.; Müller, C.E. BAY60-6583 Acts as a Partial Agonist at Adenosine A2B Receptors. J. Pharmacol. Exp. Ther. 2014, 349, 427-436. [CrossRef]

50. Katebi, M.; Soleimani, M.; Cronstein, B.N. Adenosine A2Areceptors play an active role in mouse bone marrow-derived mesenchymal stem cell development. J. Leukoc. Biol. 2008, 85, 438-444. [CrossRef]

51. Corciulo, C.; Wilder, T.; Cronstein, B.N. Adenosine A2B receptors play an important role in bone homeostasis. Purinergic Signal. 2016, 12, 537-547. [CrossRef] 
52. Shih, Y.-R.V.; Liu, M.; Kwon, S.K.; Iida, M.; Gong, Y.; Sangaj, N.; Varghese, S. Dysregulation of ectonucleotidase-mediated extracellular adenosine during postmenopausal bone loss. Sci. Adv. 2019, 5, eaax1387. [CrossRef] [PubMed]

53. Kara, F.M.; Chitu, V.; Sloane, J.; Axelrod, M.; Fredholm, B.B.; Stanley, E.R.; Cronstein, B.N. Adenosine A 1 receptors (A 1 Rs) play a critical role in osteoclast formation and function. FASEB J. 2010, 24, 2325-2333. [CrossRef] [PubMed]

54. He, W.; Cronstein, B.N. Adenosine A1 receptor regulates osteoclast formation by altering TRAF6/TAK1 signaling. Purinergic Signal 2012, 8, 327-337. [CrossRef] [PubMed]

55. Kara, F.M.; Doty, S.B.; Boskey, A.L.; Goldring, S.; Zaidi, M.; Fredholm, B.B.; Cronstein, B.N. Adenosine A1receptors regulate bone resorption in mice: Adenosine A1receptor blockade or deletion increases bone density and prevents ovariectomy-induced bone loss in adenosine A1receptor-knockout mice. Arthritis Rheum. 2010, 62, 534-541. [CrossRef]

56. Mediero, A.; Kara, F.M.; Wilder, T.; Cronstein, B.N. Adenosine A2A Receptor Ligation Inhibits Osteoclast Formation. Am. J. Pathol. 2012, 180, 775-786. [CrossRef] [PubMed]

57. He, W.; Mazumder, A.; Wilder, T.; Cronstein, B.N. Adenosine regulates bone metabolism via A 1, A 2A, and $\mathrm{A} 2 \mathrm{~B}$ receptors in bone marrow cells from normal humans and patients with multiple myeloma. FASEB J. 2013, 27, 3446-3454. [CrossRef]

58. Takedachi, M.; Oohara, H.; Smith, B.J.; Iyama, M.; Kobashi, M.; Maeda, K.; Long, C.L.; Humphrey, M.B.; Stoecker, B.J.; Toyosawa, S.; et al. CD73-generated adenosine promotes osteoblast differentiation. J. Cell. Physiol. 2012, 227, 2622-2631. [CrossRef]

59. Bradaschia-Correa, V.; Josephson, A.M.; Egol, A.J.; Mizrahi, M.M.; Leclerc, K.; Huo, J.; Cronstein, B.N.; Leucht, P. Ecto-5' -nucleotidase (CD73) regulates bone formation and remodeling during intramembranous bone repair in aging mice. Tissue Cell 2017, 49, 545-551. [CrossRef]

60. Wu, W.; Xiao, Z.; Chen, Y.; Deng, Y.; Zeng, D.; Liu, Y.; Huang, F.; Wang, J.; Liu, Y.; Bellanti, J.A. CD39 Produced from Human GMSCs Regulates the Balance of Osteoclasts and Osteoblasts through the Wnt/beta-Catenin Pathway in Osteoporosis. Mol. Ther. 2020, 28, 1518-1532. [CrossRef]

61. Gardinier, J.D.; Rostami, N.; Juliano, L.; Zhang, C. Bone adaptation in response to treadmill exercise in young and adult mice. Bone Rep. 2018, 8, 29-37. [CrossRef] [PubMed]

62. Wallace, J.; Rajachar, R.M.; Allen, M.R.; Bloomfield, S.A.; Robey, P.G.; Young, M.F.; Kohn, D.H. Exercise-induced changes in the cortical bone of growing mice are bone- and gender-specific. Bone 2007, 40, 1120-1127. [CrossRef] [PubMed]

63. Zarębska, E.; Kusy, K.; Słomińska, E.M.; Kruszyna, Ł.; Zieliński, J. Alterations in Exercise-Induced Plasma Adenosine Triphosphate Concentration in Highly Trained Athletes in a One-Year Training Cycle. Metabolites 2019, 9, 230. [CrossRef] [PubMed]

64. Honnor, R.C.; Dhillon, G.S.; Londos, C. cAMP-dependent protein kinase and lipolysis in rat adipocytes. II. Definition of steady-state relationship with lipolytic and antilipolytic modulators. J. Biol. Chem. 1985, 260, 15130-15138.

65. Fain, J.N.; Wieser, P.B. Effects of adenosine deaminase on cyclic adenosine monophosphate accumulation, lipolysis, and glucose metabolism of fat cells. J. Biol. Chem. 1975, 250, 1027-1034.

66. Szkudelski, T.; Szkudelska, K.; Nogowski, L. Effects of adenosine A1 receptor antagonism on lipogenesis and lipolysis in isolated rat adipocytes. Physiol. Res. 2008, 58, 863-871.

67. Vannucci, S.J.; Klim, C.M.; Martin, L.F.; LaNoue, K.F. A1-adenosine receptor-mediated inhibition of adipocyte adenylate cyclase and lipolysis in Zucker rats. Am. J. Physiol. Metab. 1989, 257, E871-E878. [CrossRef]

68. Hoffman, B.B.; Dall'Aglio, E.; Hollenbeck, C.; Chang, H.; Reaven, G.M. Suppression of free fatty acids and triglycerides in normal and hypertriglyceridemic rats by the adenosine receptor agonist phenylisopropyladenosine. J. Pharmacol. Exp. Ther. 1986, 239, 715-718.

69. Johansson, S.M.; Lindgren, E.; Yang, J.-N.; Herling, A.W.; Fredholm, B.B. Adenosine A1 receptors regulate lipolysis and lipogenesis in mouse adipose tissue-Interactions with insulin. Eur. J. Pharmacol. 2008, 597, 92-101. [CrossRef]

70. Yang, T.; Gao, X.; Sandberg, M.; Zollbrecht, C.; Zhang, X.-M.; Hezel, M.; Liu, M.; Peleli, M.; Lai, E.-Y.; A Harris, R.; et al. Abrogation of adenosine A1 receptor signalling improves metabolic regulation in mice by modulating oxidative stress and inflammatory responses. Diabetologia 2015, 58, 1610-1620. [CrossRef] 
71. Faulhaber-Walter, R.; Jou, W.; Mizel, D.; Li, L.; Zhang, J.; Kim, S.M.; Huang, Y.; Chen, M.; Briggs, J.P.; Gavrilova, O.; et al. Impaired Glucose Tolerance in the Absence of Adenosine A1 Receptor Signaling. Diabetes 2011, 60, 2578-2587. [CrossRef] [PubMed]

72. Dong, Q.; Ginsberg, H.N.; Erlanger, B.F. Overexpression of the A1 adenosine receptor in adipose tissue protects mice from obesity-related insulin resistance. Diabetes Obes. Metab. 2001, 3, 360-366. [CrossRef] [PubMed]

73. Rice, A.M.; Fain, J.N.; Rivkees, S.A. A1 adenosine receptor activation increases adipocyte leptin secretion. Endocrinology 2000, 141, 1442-1445. [CrossRef]

74. Neméth, Z.H.; Bleich, D.; Csóka, B.; Pacher, P.; Mabley, J.G.; Himer, L.; Vizi, E.S.; Deitch, E.A.; Szabó, C.; Cronstein, B.N.; et al. Adenosine receptor activation ameliorates type 1 diabetes. FASEB J. 2007, 21, 2379-2388. [CrossRef] [PubMed]

75. Figler, R.A.; Wang, G.; Srinivasan, S.; Jung, D.Y.; Zhang, Z.; Pankow, J.; Ravid, K.; Fredholm, B.; Hedrick, C.C.; Rich, S.S.; et al. Links Between Insulin Resistance, Adenosine A2B Receptors, and Inflammatory Markers in Mice and Humans. Diabetes 2011, 60, 669-679. [CrossRef]

76. Johnston-Cox, H.; Eisenstein, A.S.; Koupenova, M.; Carroll, S.; Ravid, K. The Macrophage A2b Adenosine Receptor Regulates Tissue Insulin Sensitivity. PLoS ONE 2014, 9, e98775. [CrossRef]

77. Csóka, B.; Koscsó, B.; Törő, G.; Kókai, E.; Virág, L.; Németh, Z.H.; Pacher, P.; Bai, P.; Haskó, G. A2B Adenosine Receptors Prevent Insulin Resistance by Inhibiting Adipose Tissue Inflammation via Maintaining Alternative Macrophage Activation. Diabetes 2014, 63, 850-866. [CrossRef]

78. Merighi, S.; Borea, P.A.; Gessi, S. Adenosine receptors and diabetes: Focus on the A2B adenosine receptor subtype. Pharmacol. Res. 2015, 99, 229-236. [CrossRef]

79. Pei, Y.; Li, H.; Cai, Y.; Zhou, J.; Luo, X.; Ma, L.; McDaniel, K.; Zeng, T.; Chen, Y.; Qian, X.; et al. Regulation of adipose tissue inflammation by adenosine 2A receptor in obese mice. J. Endocrinol. 2018, 239, 365-376. [CrossRef]

80. Cai, Y.; Li, H.; Liu, M.; Pei, Y.; Zheng, J.; Zhou, J.; Luo, X.; Huang, W.; Ma, L.; Yang, Q.; et al. Disruption of adenosine $2 \mathrm{~A}$ receptor exacerbates NAFLD through increasing inflammatory responses and SREBP1c activity. Hepatology 2018, 68, 48-61. [CrossRef]

81. Csóka, B.; Törő, G.; Vindeirinho, J.; Varga, Z.V.; Koscsó, B.; Németh, Z.H.; Kókai, E.; Antonioli, L.; Suleiman, M.; Marchetti, P.; et al. A 2A adenosine receptors control pancreatic dysfunction in high-fat-diet-induced obesity. FASEB J. 2017, 31, 4985-4997. [CrossRef] [PubMed]

82. DeOliveira, C.C.; Caria, C.; Gotardo, E.M.F.; Ribeiro, M.L.; Gambero, A. Role of A 1 and A 2A adenosine receptor agonists in adipose tissue inflammation induced by obesity in mice. Eur. J. Pharmacol. 2017, 799, 154-159. [CrossRef] [PubMed]

83. Ruan, C.; Gao, P. GW29-e1353 A2A Receptor Activation Attenuates Hypertensive Cardiac Remodeling via Promoting Brown Adipose Tissue-Derived FGF21. J. Am. Coll. Cardiol. 2018, 72, C41. [CrossRef]

84. Lahesmaa, M.; Oikonen, V.; Helin, S.; Luoto, P.; Din, M.U.; Pfeifer, A.; Nuutila, P.; Virtanen, K.A. Regulation of human brown adipose tissue by adenosine and A2A receptors-Studies with [15O] $\mathrm{H}_{2} \mathrm{O}$ and [11C]TMSX PET/CT. Eur. J. Nucl. Med. Mol. Imaging 2018, 46, 743-750. [CrossRef]

85. Xiao, C.; Liu, N.; Jacobson, K.A.; Gavrilova, O.; Reitman, M.L. Physiology and effects of nucleosides in mice lacking all four adenosine receptors. PLoS Biol. 2019, 17, e3000161. [CrossRef]

86. Gnad, T.; Navarro, G.; Lahesmaa, M.; Reverte-Salisa, L.; Copperi, F.; Cordomi, A.; Naumann, J.; Hochhäuser, A.; Haufs-Brusberg, S.; Wenzel, D.; et al. Adenosine/A2B Receptor Signaling Ameliorates the Effects of Aging and Counteracts Obesity. Cell Metab. 2020, 32, 56-70.e7. [CrossRef]

87. Jacobson, K.A.; Tosh, D.K.; Jain, S.; Gao, Z.-G. Historical and Current Adenosine Receptor Agonists in Preclinical and Clinical Development. Front. Cell. Neurosci. 2019, 13, 124. [CrossRef]

88. Ishikawa, J.; Mitani, H.; Bandoh, T.; Kimura, M.; Totsuka, T.; Hayashi, S. Hypoglycemic and hypotensive effects of 6-cyclohexyl-2'-O-methyl-adenosine, an adenosine A1 receptor agonist, in spontaneously hypertensive rat complicated with hyperglycemia. Diabetes Res. Clin. Pract. 1998, 39, 3-9. [CrossRef]

89. Zannikos, P.N.; Rohatagi, S.; Jensen, B.K. Pharmacokinetic-pharmacodynamic modeling of the antilipolytic effects of an adenosine receptor agonist in healthy volunteers. J. Clin. Pharmacol. 2001, 41, 61-69. [CrossRef]

90. Shah, B.; Rohatagi, S.; Natarajan, C.; Kirkesseli, S.; Baybutt, R.; Jensen, B.K. Pharmacokinetics, Pharmacodynamics, and Safety of a Lipid-Lowering Adenosine A1 Agonist, RPR749, in Healthy Subjects. Am. J. Ther. 2004, 11, 175-189. [CrossRef] 
91. Dhalla, A.K.; Santikul, M.; Smith, M.; Wong, M.-Y.; Shryock, J.C.; Belardinelli, L. Antilipolytic Activity of a Novel Partial A1 Adenosine Receptor Agonist Devoid of Cardiovascular Effects: Comparison with Nicotinic Acid. J. Pharmacol. Exp. Ther. 2007, 321, 327-333. [CrossRef] [PubMed]

92. Dhalla, A.K.; Wong, M.Y.; Voshol, P.J.; Belardinelli, L.; Reaven, G.M. A1 adenosine receptor partial agonist lowers plasma FFA and improves insulin resistance induced by high-fat diet in rodents. Am. J. Physiol. Metab. 2007, 292, E1358-E1363. [CrossRef] [PubMed]

93. Staehr, P.M.; Dhalla, A.K.; Zack, J.; Wang, X.; Ho, Y.L.; Bingham, J.; Belardinelli, L. Reduction of Free Fatty Acids, Safety, and Pharmacokinetics of Oral GS-9667, an A1Adenosine Receptor Partial Agonist. J. Clin. Pharmacol. 2013, 53, 385-392. [CrossRef] [PubMed]

94. Chen, J.-F.; Cunha, R.A. The belated US FDA approval of the adenosine A2A receptor antagonist istradefylline for treatment of Parkinson's disease. Purinergic Signal. 2020, 16, 1-8. [CrossRef] [PubMed]

95. Charvin, D.; Medori, R.; Hauser, R.A.; Rascol, O. Therapeutic strategies for Parkinson disease: Beyond dopaminergic drugs. Nat. Rev. Drug Discov. 2018, 17, 804-822. [CrossRef]

(C) 2020 by the authors. Licensee MDPI, Basel, Switzerland. This article is an open access article distributed under the terms and conditions of the Creative Commons Attribution (CC BY) license (http://creativecommons.org/licenses/by/4.0/). 